\title{
Chapter 3 \\ APIEL Compulsory Course: Environmental Challenges and Leadership in Asia
}

\author{
Motoharu Onuki and Kyoungjin J. An
}

\begin{abstract}
APIEL compulsory course, Environmental Challenges and Leadership in Asia (ECLA) discuss the human sustainability on earth by looking into the critical environmental issues in Asia and defines Environmental Leadership along with the environmental literacy and skills which are highly required in developing a sustainable society. Since many countries in Asia are densely populated and undergoing various development stages, Asia stands as the core region when considering our future global sustainability.

The feature of this course is the combination of lectures and case studies including interactive dialogues between teachers and students, group discussion and presentation in the classroom. Case studies were provided to understand discourses on industrialization (Minamata disease case), globalization (China's air pollution case) and recent urbanization (Korea's reclamation case). Students experientially learn communication, facilitation, and leadership skills by resolving tension between students from different academic fields. Therefore, this course provides platform for the field exercises where students can practice what they learn in the class.
\end{abstract}

Keywords China's environmental problems - Global environmental problems - Industrial pollution problems $\bullet$ Leadership education $\bullet$ Minamata disease $\bullet$ Urban environmental problems

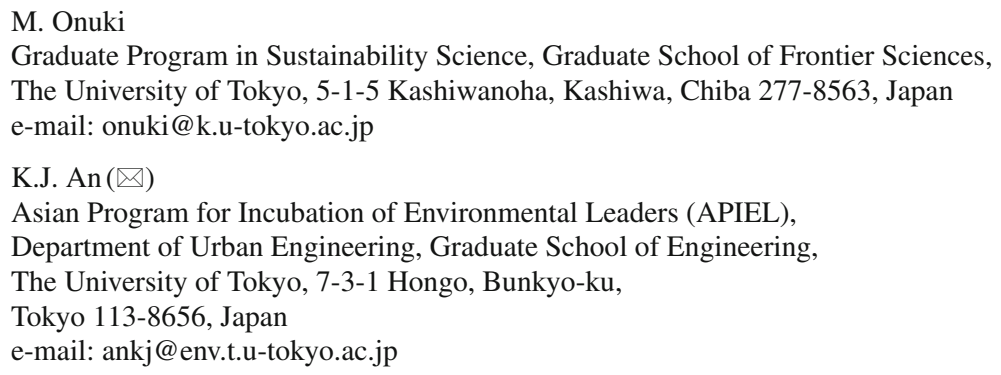




\subsection{Introduction}

Asia is showing increasing signs of demographic fatigue in its quest to provide for all the needs and wants of its exploding population. Of the world's more than six billion people, approximately 3.5 billion live in Asia. Two Asian countries combined-China and India-account for more than one-third of the global population; each of these nations has for more than one billion people. Environmental degradation has been one of the most visible manifestations of this evolving struggle. However, in most Asian countries, environmental activism or leadership is a fairly recent phenomenon. For example, in China, the government by the mid-1990s had started to tolerate environmental activism, as long as it focused on solving specific problems rather than criticizing government policies and decisions. Two prime indicators of environmental legislation and enforcement agencies were introduced in the ECLA class (see Fig. 3.1) to illustrate Asia's institutional level of environmental leadership and reform.

Japan was the first country in Asia to become industrialized and to face serious environmental disasters such as Minamata disease, so it was the first Asian country to pass basic environmental laws (1967) and to establish a ministry of the environment (1971) as shown in Fig. 3.1. Singapore established its own environmental ministry 1 year later (1972), with China and Malaysia following in 1974. Since then, the second wave of environment ministries in Asia occurred in the late 1980s and early 1990s. In most Asian countries, basic environmental legislation lagged behind the introduction of environment ministries.

Asia is the fastest-growing region measured by population growth as well economic development (though countries are at different stages), thus Asian economies provide many hints to our students to deal with evolving environmental

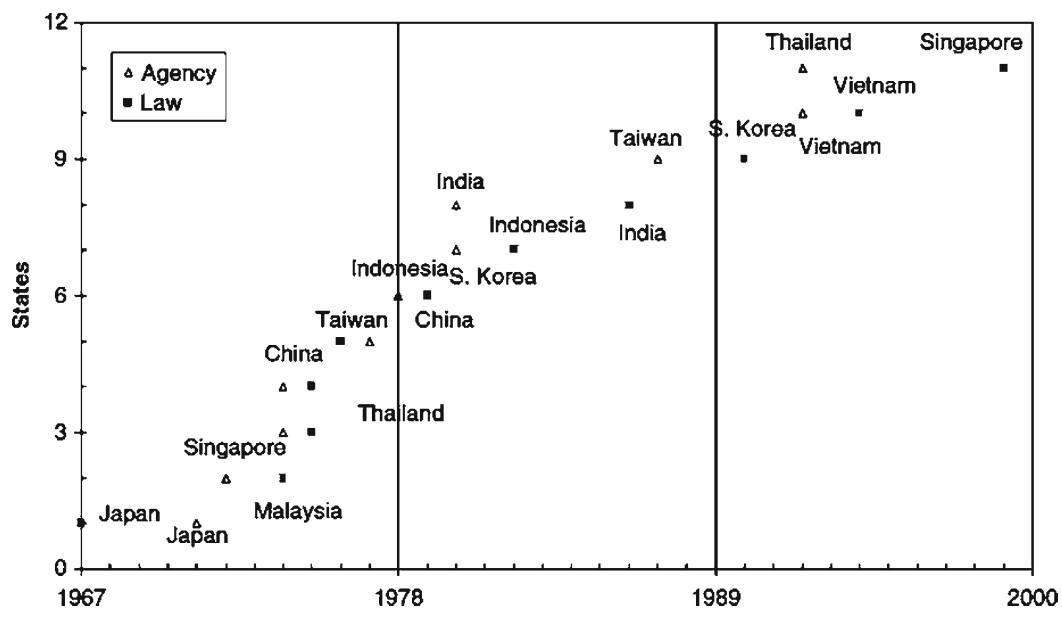

Fig. 3.1 Establishment of environmental governance, 1967-2000 (Source: UNEP-RRCAP, 2003) 
issues associated with a wide range of development and the required leadership skills. Therefore, this course aims to review environmental issues in Asia from the history to up to date; to tackle such problems with the key of sustainably and finally to foster future environmental leaders highly required in developing a sustainable society.

The rest of this chapter consist of three sub chapter as follows: first, Sect. 3.2 describes featured ECLA's education methods in the class mainly though creating a vision, interviewing environmental leaders and debate. Second, Sect. 3.3 provides details material used for three case studies developed for ECLA. Authors carefully selected prominent case studies from discourses on industrialization in 1960s with a typical example of an industrial pollution problem that Japan has experienced (Minamata disease case); globalization (China's air pollution case) with climate change; and recent urbanization in great needs of public participation with Korea's Cheonggyecheon Restoration case in 2000s. Third and finally, we discuss and summarize main features of the compulsory course followed by overall discussion and conclusion.

\subsection{Education Methods in ECLA}

Course syllabus was developed and modified each year over the past 4 years in order to meet objectives of the course as shown in Fig. 3.2.

The following section describes the details about featured ECLA's education methods in the class mainly though creating a vision, interviewing environmental leaders and debate.

\subsubsection{Creating a Vision Through Group Discussion}

During the very first ECLA class, the authors asked students to choose one environmental project from his or her own country and write an action plan for a funding proposal to the World Bank. About 40 students met and formed 7 groups: 5 from Department of Urban Engineering (UE) and 2 from Graduate Program in Sustainability Science (GPSS), The University of Tokyo. They then negotiated to decide on only one project. In doing this, the students were required to identify the real-world problems and create a vision through collaboration with various stakeholders in each locality. Proposals from UE and GPSS students are summarized in Table 3.1 and are categorized into ten emergent environmental issues in Asia taught by the author based on a review of the literature and authors' experiences.

As we can see from the table, students address the issue of population growth associated with poverty and land use, agriculture, forest, water, and energy. However, biodiversity, air quality, global warming, and environmental activity have not been tackled. The teachers another concern is that in the midst of competing demands, 

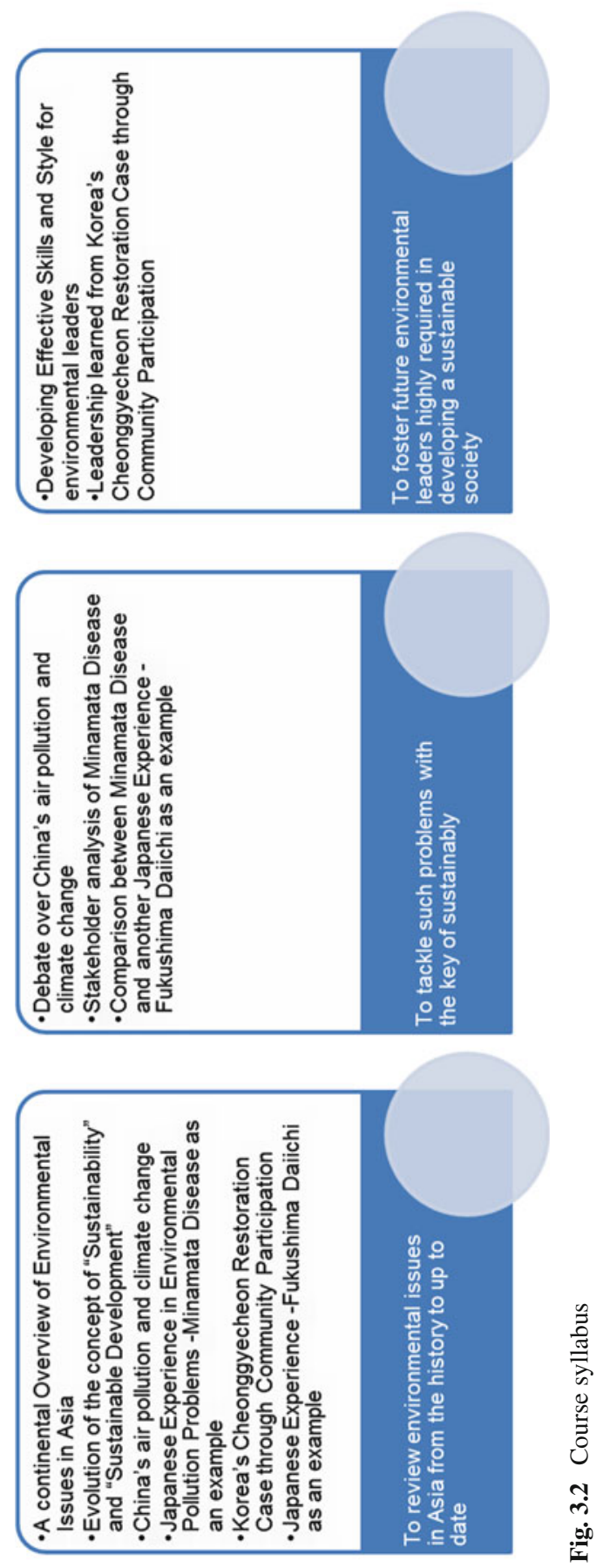
Table 3.1 Emergent environmental issues in Asia and Students' interest in the environment (ECLA class of 2012)

\begin{tabular}{|c|c|}
\hline Author (from Hillstrom and Hillstrom [1]) & UE students \\
\hline $\begin{array}{l}\text { Population and land use } \\
\text { Food security, consumerism, urbanization } \\
\text { and migration, and land } \\
\text { management, etc. }\end{array}$ & $\begin{array}{l}\text { Poverty issue: education, } \\
\text { training skills in India } \\
\text { Sustainable regional } \\
\text { rehabilitation in the } \\
\text { Tohoku region in Japan } \\
\text { (land use) }\end{array}$ \\
\hline
\end{tabular}

GPSS students

Biodiversity

Land conversion and fragmentation

Alien species by trade, in potted plants and shipment of crops

Overharvesting and the trade in Asian wildlife

Park, preserves, and protected areas

Conservation of biodiversity

National parks, wildlife sanctuaries, and nature reserves

Forests

Sustainability of forest, agriculture and other systems based on ecosystem dynamics

People became more knowledgeable about the limits of the earth because of natural systems

Sustainability became a very old idea and social goal

Agriculture

Continual increase in the world's demand for food

Attempts to slow human population growth in order to reduce future food demand

Intensification of agricultural production

Increased use of pesticides and herbicides, decreased soil quality, conversion of forest

Promotion of sustainable agricultural use and management by education and training in Vietnam (less fertilizer)
Forest conservation: Indonesia

Activity: eco-tourism

Promotion of organic farming in China: solve problems of nitrate groundwater contamination and wetlands to agriculture, damage to watersheds from runoff, and the deterioration of rural communities

Freshwater

Rehabilitation of major rivers ruined by decades of heavy pollution

Acutely vulnerable to weather-related disasters

Industrialized countries (e.g., Japan, Singapore, South Korea and Taiwan) clearly have fewer problems providing access to safe water, while in developing country access to safe drinking water is often a luxury, sometimes only available to the affluent 
Table 3.1 (continued)

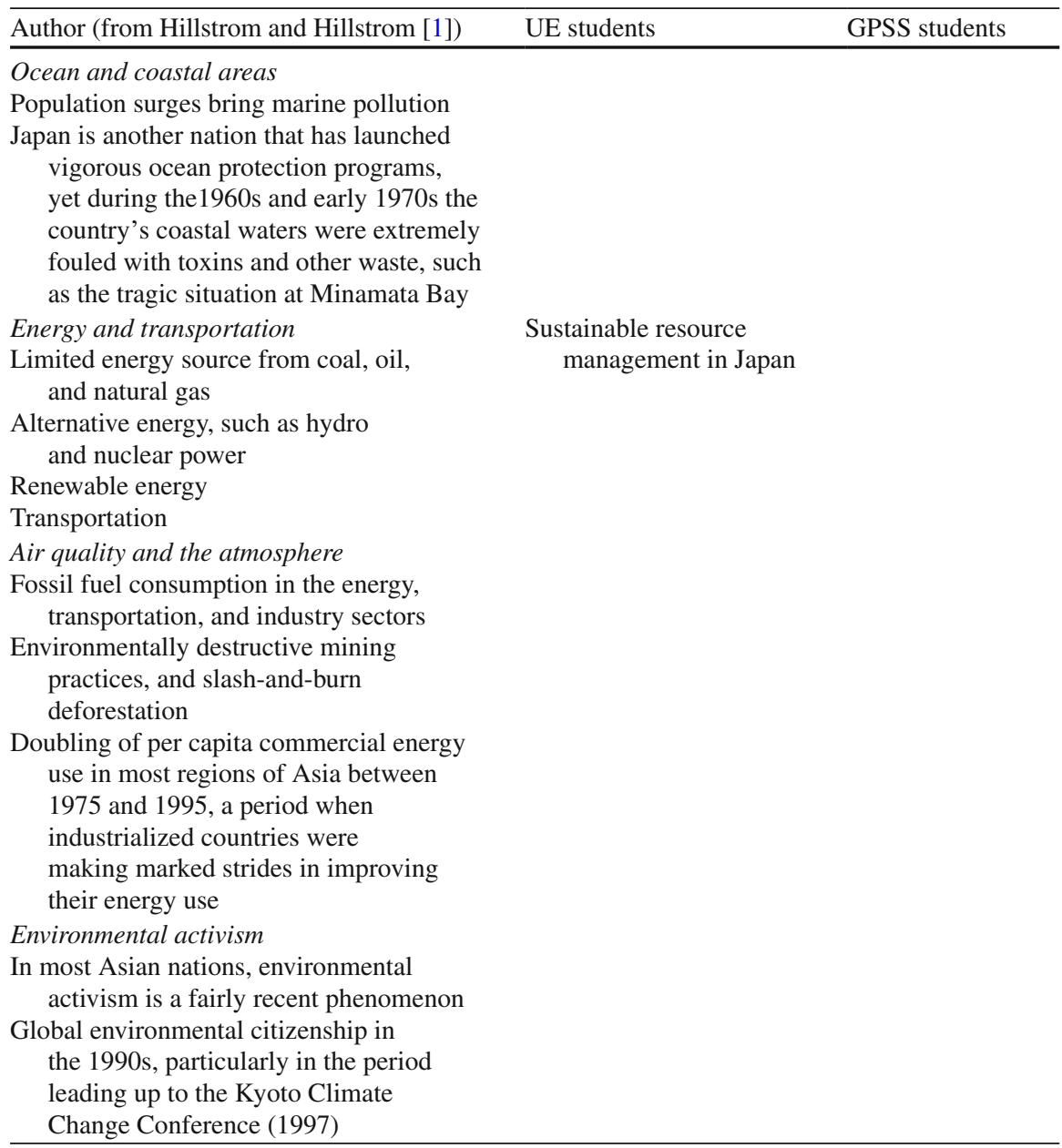

the priorities are for easy or low cost tasks. In other words, we have limited leadership capacity to tackle these pressing issues. Leaders need to provide a vision and solutions at this stage, though many of the problems seem formidable. However, this exercise allowed future leaders (the students) to practice setting clear priorities from among the competing needs and demands.

\subsubsection{Interview Environmental Leaders}

Gordon and Berry [2] stressed the difference between environmental leadership from other types of leadership. The Central premise is that the difference of the 
environmental leadership is based on the unique characteristics environmental problems that require long time to solution, complexity and uncertainty, emotionally charged situations, an incomplete and scattered science base, and the necessity for integration.

This section discusses the relationship between leadership and environment issues to be solved by conducting survey and interview students in class. The authors reviewed successful examples of environmental leaders in Asia with students and used survey questions for young leader's perspectives on environmental leader. The survey questions are used to discuss how students see today's environmental leaders: included important social trends or conditions affecting today's environmental leaders, major barriers facing today's leaders, how leaders emerge in their individual organizations, and the five characteristic the students think are most important for today's leader. Based on this subjective analysis, more objective statements about leadership were written. The results are summarized in Table 3.2.

Most of the respondents agreed with statements 2 and 4: "Men and women often have different environmental leadership skills and styles" and "Different people lead in the organization at different times." These responses showed that future environmental leaders clearly realize the complexity of environmental issues, and that what are required of them are flexibility and the ability to work with different people at different times. In other words, for the development of a sustainable future, education or training in an organization should be multifaceted. Gordon and Berry also explained that leaders perceive leadership as a function diffused throughout an organization, not the sole property of a leader based on his/her position or title, but rather every member of an organization must be prepared to lead when his/ her turn or time comes. More interestingly, the respondents agreed more positively with statement 7 "Leaders today are more process, rather than product, oriented" and also with statement 12 "Leadership today is more difficult than in the past." This is in line with the reason why APIEL puts a high value on communication among the stakeholders to reach a consensus and promote a clear vision: APIEL emphasizes the development of "process and participation" leaders rather than "command and control" leaders.

The most controversial survey results were those for statement 9 "Command and control leadership is still necessary at times for environmental leadership" and statement 10 "Environmental leaders cannot lead without authority." Half of the respondents seem to agree with these statements. This suggests that participatory, collective leadership in this context is not yet mature and requires time and energy. The respondents acknowledged that control leadership is still required to drive change.

Finally, the results for statement 11 verified our strong belief that leadership skills and styles can be learned, and among these skills, the communication skill is an important key factor for leadership development. The following section describes how in-class teaching helps to develop communication and debating skills, using a case study: China's challenge for climate change. 


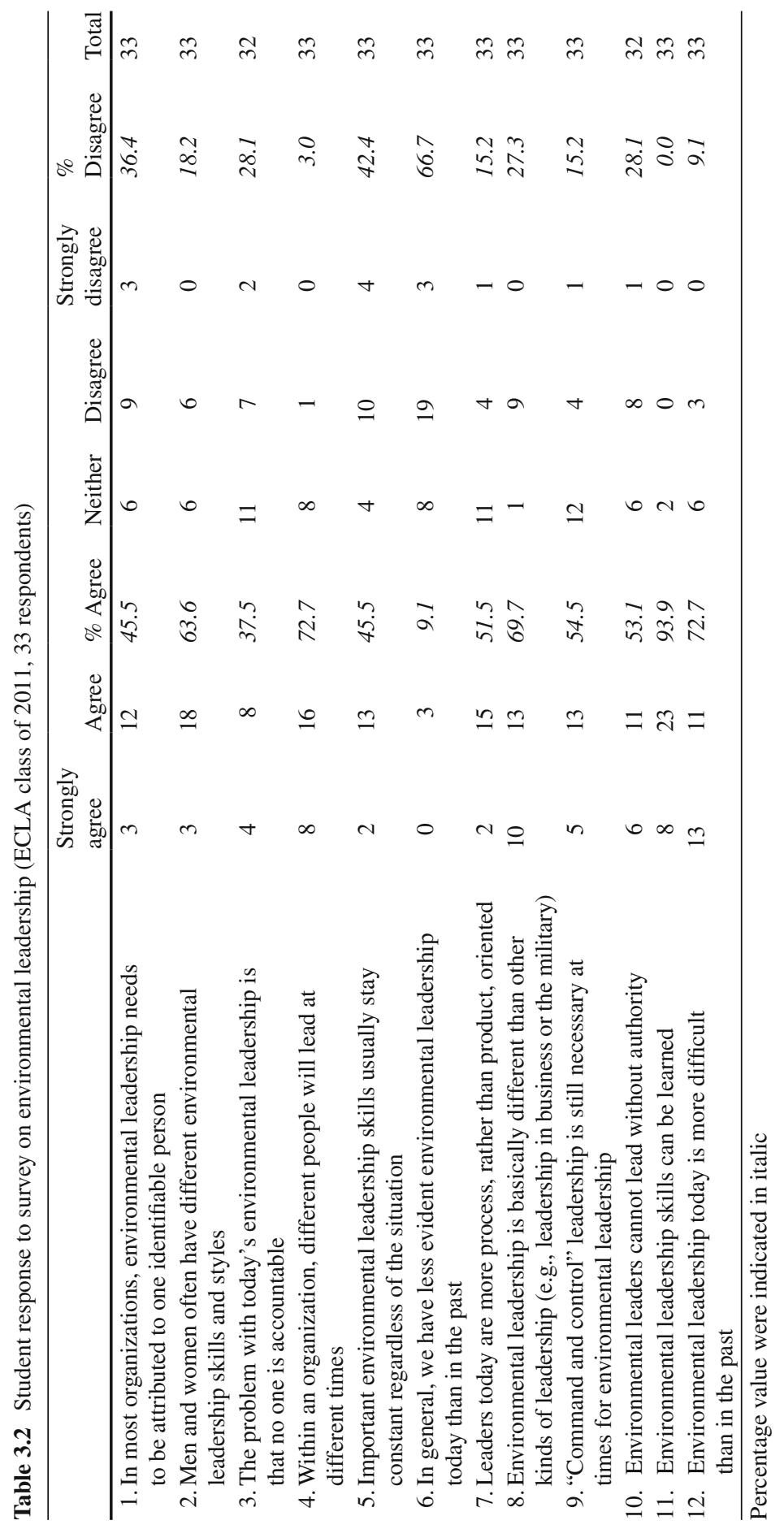




\subsubsection{Communication Practice Trough Debates}

\subsubsection{Global Communication}

Most APIEL students agree with the idea that communication, listening, and interpersonal skills are the most important leadership characteristics. Global communication for climate change made a breakthrough following the Kyoto Protocol to the United Nations Framework Convention on Climate Change: countries were urged to take a proactive stance and mitigate their $\mathrm{CO}_{2}$ production according to their economic growth. The first Earth Summit in Rio in 1992 focused on biodiversity, global warming, and forest initiatives. In 2002, the second Global Summit on Sustainable Development (Rio +20) set out to resolve the conflict created by the needs of rich and poor countries and their impacts on the global economy [3]. The environment is no longer an isolated issue; it is at the heart of our global future. By 1995, countries realized that emission reduction provisions from the Rio convention were inadequate. Two years later, the Kyoto Protocol legally bound developed countries to emission reduction targets. The Kyoto Protocol's first commitment period started in 2008 and ends in 2012. One of the greatest global concerns is China's growing contribution to climate change. (China is the second largest contributor to climate change.) China has signed the Kyoto Protocol and has initiated some projects - with EU members-under the protocol. After 4 years of negotiations, the question of what happens beyond 2020 was also answered at Durban. The decision on the green climate fund extension of the Kyoto Protocol comes into effect by 2020. These include reduction pledges for 2020 and the goal of keeping global warming below $2{ }^{\circ} \mathrm{C}$. There will be a joint implementation by China, India, and the US.

Learning from this global communication, the difficulty becomes apparent when countries, who would all benefit from addressing climate change, accept a global legal framework. However, China's goal to generate $10 \%$ of their power from renewable sources by 2010 was unlikely to have a significant impact on its contribution to climate change.

\subsubsection{Communication Practice in Class}

ECLA students - from UE and GPSS - communicated using debates on whether China has to play a leadership role on climate change. There are some special terms used in the debates. The opinion in a debate is called a resolution. The debate team that agrees with the resolution is called the affirmative team. The team that disagrees with the resolution is the negative team. The people in charge of evaluating the debate are called judges. The author has been a moderator at these debates. Interestingly, after discussion among the students, the ECLA class was divided into negative (UE) and affirmative (GPSS) teams. In the debates, the goal has been to persuade the judge and the audience that their opinion is the most 
compelling. To persuade the judge and the audience, the speaker should have strong arguments, which means tough reasoning, factual support, and refutations as well as a strong manner, which includes gestures, eye contact, posture, voice, and the use of humor.

Throughout the debating exercise, scientific evidence supporting their reasoning should be clear and easy to understand. In the rebuttal, each team explains where their points stand, and where the points of the other team fall, from the social and economic perspectives. Overall, we try not to lose our senses of humor. In addition, the students are able to practice listening to understand what each speaker is saying, as well as good teamwork, and expressing their own points while refuting the other team.

\subsection{Materials Used for Case Studies in ECLA}

This sub chapter introduces material used for three case studies in detail. As illustrated in Fig. 3.3, based on provided material, students analyze the fact and interacted with teacher to build leadership capacity through and through.

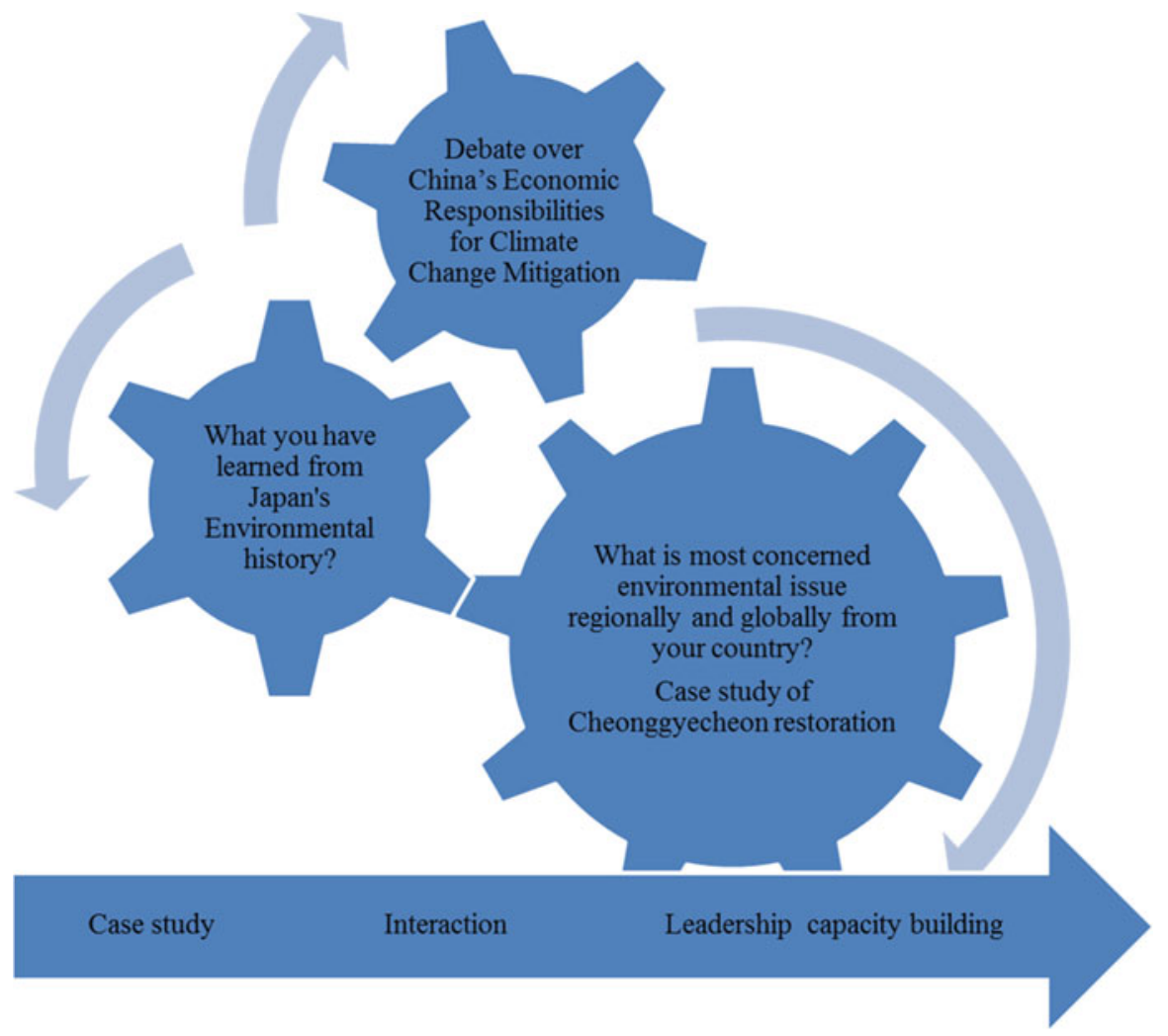

Fig. 3.3 Material used for case studies in ECLA 


\subsubsection{Minamata Disease and Japan's Experience with Industrial Pollution}

For Japan, industrial pollution originates as environmental problems. Why they happened and how they were overcome give us several lessons for preventing new pollution problems from occurring in Japan or in other parts of the world.

Minamata disease is a typical example of an industrial pollution problem that Japan has experienced. Minamata disease, a disease of the central nervous system, is caused by eating fish and shellfish contaminated with methyl mercury compounds. These compounds were discharged into the sea at the Shin Nihon Chisso (hereafter Chisso) plant in Minamata. The compounds accumulated in the marine life [4]. Since it was one of the first severe industrial or environmental pollution problems in Japanese history, limited knowledge and lessons were available at that time. It took a long time to understand and overcome what was occurring. Minamata disease is one of the largest and longest-lasting pollution problems in Japan, and the Minamata disease issue represents nearly all aspects of pollution problems. For these reasons, this Mianamta case provides an essential case study for fostering environmental leaders.

The objective of this case study is to learn the following aspects of environmental pollution: (1) environmental pollution ultimately harms people, and protecting the environment is critical, (2) economic growth and human health/rights, (3) discrimination, the social divide, and environmental justice (4) science, technology, and society, (5) environmental science and environmental engineering, (6) environmental economics, and (7) post-modern and risk issues. This list shows that the issues surrounding Minamata disease are ongoing. It also touches on the most advanced issues related to the environment and sustainability.

\subsubsection{Environmental Pollution Ultimately Harms People and Protecting the Environment Is Critical}

The first step of this case study is to understand the tragic consequences of Minamata disease. Through this step, students learn how a polluted environment ultimately harms people and that protecting the environment is essential. The tragic experiences of the victims include not only the disease itself but also how other people treated them.

In Minamata today, several of the victims are registered as storytellers and opportunities to listen to their stories are organized. Many elementary or junior high schools are taking advantage of this storytelling for their social study courses. Storytelling is also used during training courses at universities and companies. ECLA also shows a video of the storytellers and has students read books, such as Kugai Jodo (Paradise in the Sea of Sorrow) written by Ishimure [5] to help them understand the victims' experiences. 


\subsubsection{Economic Growth and Human Health/Rights: Chisso's Irresponsibility}

One of the reasons why Minamata disease was so widely spread was Chisso's irresponsibility. Chisso conducted an experiment called the "cat number 400 experiment" to reveal the cause of the disease by themselves. In this experiment, a cat that had been given food to which factory effluent had been added showed clear symptoms of Minamata disease. This result demonstrated that Chisso's discharge was the causative substance in the environment. It indisputably showed Chisso's responsibility for the disease, even though the pollutant had not yet been identified as methyl mercury. However, the results of the experiment were not published. Chisso placed the highest priorities on earning a profit. In order to continue operating the plant, Chisso buried the results of the experiment. Moreover, when Kumamoto University pointed out that methyl mercury was causing the disease, Chisso raised questions. It is obvious that Chisso was putting profits before people and ignoring human rights. The most important point here is to let students think about what they might have done if they had been a researcher or engineer inside Chisso.

\subsubsection{Economic Growth and Human Health/Rights: Citizens' Awareness}

We also have to remember that many Minamata citizens supported Chisso, because Minamata was heavily dependent on Chisso for tax revenue. Without Chisso, Minamata would have been a small local village in western Japan. Some citizens considered Minamata disease as someone else's problem or even as an annoyance. Others thought that a certain amount of "pollution" must be acceptable in exchange for prosperity in Minamata. Moreover, to people living in Tokyo, Minamata disease was an issue occurring far away from them and was not their concern. Many storytellers mention that Minamata disease is a disease of the modern age where people want too much convenience and too much prosperity based on industry and technology.

\subsubsection{Discrimination, the Social Divide, and Environmental Justice}

Most of the patients identified in the early stages were fishermen and their families. Since fishermen in Minamata originally came from the Amakusa Islands (on the other side of the Shiranui Sea), they were considered outsiders and were lower down in the social hierarchy. This is another reason why the patients faced discrimination. Harada [6] and Ui [7] have denied that industrial pollution created "abandoned" victims. Instead, they argue that industrial pollution problems occur where there are weak people and industrial pollution hits them. Note: today, Minamata 
City has been trying to re-develop community relations under the concept of moyainaoshi or re-connecting [4].

\subsubsection{Science, Technology, and Society}

Chisso's irresponsible attitude has been discussed in the previous section. If the result of the cat number 400 experiments had been published in 1959, countermeasures for Minamata disease would have been taken and the number of victims would have been completely different. However, another factor, from the perspective of "science, technology and society", has also been pointed out.

When Kumamoto University was concluding that methyl mercury as a causative substance, Chisso raised counterarguments:

1. Why was it not until 1954 that Minamata disease suddenly occurred, although Chisso has been operating since 1932 ?

2. Why did Minamata disease occur only in Minamata although many acetaldehyde factories had been using the same chemical process?

Once counterarguments are raised, scientists usually try to respond. In spite of a government order forcing Chisso to submit wastewater samples, scientist tried to answer these questions one by one, although what was urgently needed was only to prove that factory effluent was causing the disease.

In the field of science, there are many unsolved problems, and scientists are always doing research. However, government and citizens expect scientists to come up with a $100 \%$ complete answer. If even $1 \%$ remains unsolved, governments often wait. They use the fact that arguments are still continuing as a reason why they aren't taking any measures for the relief of victims. This relationship between the scientific community and government has been called the "resonance of scientists and government" by Sugiyama [8], and Harada [6] mentioned that the unsolved $1 \%$ should not be used as an excuse for corporations or governments to avoid accepting responsibility. Ui mentioned that there is no neutral standpoint with industrial pollution [7].

\subsubsection{Environmental Science and Environmental Engineering}

The "resonance of scientists and government" was pointed out in the previous section. Relief for victims should start even if some issues remain. At the time, the cat number 400 experiments were enough evidence to start relief measures. However, scientific study is still necessary, especially for preventing the same mistakes from occurring in the future; scientific study must continue.

The two questions raised by Chisso were finally answered by Nishimura and Okamoto [9] more than 40 years later. They revealed the chemical reaction pathways, determined the kinetic parameters of methyl mercury production under several conditions, and finally determined that switching the oxidant from permanganate 
to nitric acid in 1951 was the cause of the sudden increase of methyl mercury discharge. This was the answer to question 1 (above). However, using nitric acid as an oxidant was the normal practice in acetaldehyde production, which didn't cause any problem in other factories or companies in Japan. Nishimura finally found that the high concentration of chlorine ions at the Chisso factory was the key difference. When chlorine ion concentrations are low, during the normal process (using nitric acid as an oxidant) only tiny amounts of methyl mercury are produced, but when the chlorine ion concentration is high, methyl mercury is vaporized and easily discharged to the outside. That was the answer to question 2 [9]. Even though it took 40 years to answers these questions, they are still important examples of environmental scientific research, and worth studying.

\subsubsection{Environmental Economics}

Once the environment is polluted, it takes a long time and a huge cost for recovery. When pollution diseases and victims appear, it is nearly impossible to recover from the damage, and compensation can be enormous. From the viewpoint of environmental economics, the cost for preventive measures, including wastewater treatment and developing production processes that don't discharge wastewater, is cheaper than the cost of compensation and recovery of the environment [10]. The quality of the environment started to dramatically improve once this fact was widely recognized by industry, and after environmental regulations were established. This is the Japanese government's message to other countries, especially those who are currently developing rapidly.

It is important to remember that for establishing the legal framework for compensation and for developing environmental regulations we had to see victims suffering from the disease and being discriminated against, as well as having to experience lawsuits. How to reach the point of realizing that prevention is cheaper than compensation without these bitter experiences is the most important point in the class.

\subsubsection{Post-Modern Issues: Health Risks and Low-Level Exposure}

As discussed above, most Japanese people consider the Minamata disease issue solved and finished, and that it is full of lessons to be learned. However, the Minamata disease issue has not yet been finalized. Since 1968, when the Japanese government officially declared that Minamata disease was an industrial pollution problem caused by Chisso and Chisso agreed to compensation payments, many patients have been applying to be certified as victims so that they can be paid. However, many of these claims were rejected or were left pending. This is because the criteria for Minamata disease certification have been based on exhibiting the symptoms of Hunter-Russell syndrome. Hunter-Russell syndrome was discovered after methyl mercury poisoning was found in British factory workers who were producing disinfectants for seeds. It is characterized by five symptoms: numbness 
and pain in the extremities, dysarthria, ataxia, auditory disorders, and concentric constriction of the visual field. However, Minamata disease was caused by methyl mercury poisoning following the consumption of fish and shellfish contaminated by environmental pollution. The levels of contamination and pollution varied; therefore the way in which each symptom appeared also varied. This is why the criteria for official certification are considered to be too strict. Sufferers who did not have acute symptoms - perhaps only one or two symptoms (sensory disorder, numbness, etc.)—were left uncertified as victims.

Since several thousand applications were rejected or left pending in the 1990s, the Japanese government decided in 1995 to relieve these "uncertified" patients by paying their medical expenses and lump-sum amounts. Patient support groups are requesting large-scale medical checkups and revised criteria for official certification of Minamata disease. However, the Japanese government decided to review uncertified patients using different criteria instead of changing the official legal criteria. For political, social, and economic reasons, the criteria for diagnosing Minamata disease are not well defined and detailed scientific knowledge on the minimum level of Minamata disease (or methyl mercury poisoning) is still not available. More scientific data and large-scale medical checkups are necessary to understand the overall picture of Minamata disease as well as the entire mechanism for environmental pollution caused by the methyl mercury discharged by Chisso. Why hasn't this been done? Of course, the extent of suffering of "uncertified" Minamata disease patients is generally smaller than typical acute Minamata disease patients found in 1950s and 1960s. Nonetheless, when we try to definitively answer this question, we may well face renewed discussions similar to those outlined above. This is why the authors think the Minamata disease issue has not yet been put to rest and is still an example of one of the hottest topics in environmental issues: health risks and low-level exposure.

\subsubsection{China's Air Pollution Case Over Last Three Decades}

\subsubsection{China's Economic Growth}

Over the last three decades, why has China's environment been drawing so much worldwide attention, along with its rapid economic growth? The rise of China as an economic power is one of the most remarkable stories of the latter half of the twentieth century. There were annual growth rates of from $8 \%$ to $12 \%$ of GDP, and by the end of 2011 China had become the second largest economy, after the United States. However, the progression was different from other developed countries. For instance, Japan progressed through the stages of industrialization, urbanization, and globalization over a much different time span. But China's economy boomed in the face of a raging wind of concurrent industrialization, urbanization and globalization. In China, industrialization depends heavily on intensive energy and resource use, urbanization is not based on a sustainable model, and globalization, through exporting many goods and absorbing manufacturing from other countries, 
has led people to derisively call China the "world's factory." At the same time, this growth has occurred without much consideration for the environment. Growth has placed tremendous pressure on China's environment. Building on centuries of environmental degradation and pollution, the very rapid industrialization of the last quarter century has contributed to some of the highest rates of air and water pollution in the world, as well as severe land degradation, and a range of other emerging resource challenges; among them all, the most visible of China's environmental challenges is air pollution [11].

\subsubsection{China's Air Pollution}

China's air pollution is due to an overwhelming reliance on coal for energy production. China relies on coal for approximately $70 \%$ of its energy, consuming about 1.96 billion tons in 2004 . The carbon dioxide emission rate reached $1.6 \mathrm{GtC}$ (gigatons of carbon or $10^{15} \mathrm{~g}$ carbon) per year in 2006 [12], and China has become the world's largest emitter of sulfur dioxide. Moreover, by 2020, transportation experts anticipate that China will have at least 110-160 million cars on its roads. Today, China is attempting to push forward with renewable energy and with alternative fuels, such as compressed natural gas.

\subsubsection{Korea's Cheonggyecheon Restoration Case Through Community Participation}

On July 17, 2009, 5 years after the completion of the Cheonggyecheon project, the New York Times reported that the restoration was part of an expanding environmental effort in cities around the world to "daylight" rivers and streams by "peeling back pavement" that was built to bolster commerce and serve automobile traffic decades earlier [13].

\subsubsection{History of Cheonggyecheon and Leader's Attitude}

In Korean, Cheonggyecheon means "clean water stream" and this area of Seoul once had deep significance for the people living there. It runs through the city center. Seoul was chosen as the capital of Korea more than 600 years ago, and was positioned among four mountains: ones to the east, west, north, and south. Cheonggyecheon provided a cultural space and shelter before it was covered over with a road. For a long time, Cheonggyecheon was both a flood control channel and a place to wash laundry. However, by the 1940s, the stream had begun to fill up with sewage and trash, and it became a slum area after the Korean War. Since 1958, the stream was gradually covered over with a concrete road for two main reasons: filthy water (and an unsafe environment that made people lose interest in the area) 
Table 3.3 History of Cheonggyecheon

\begin{tabular}{lll}
\hline & Stream status & $\begin{array}{l}\text { Leaders' attitude to } \\
\text { waterway control }\end{array}$ \\
\hline $\begin{array}{l}\text { 1400s-1500s } \\
1600 \mathrm{~s}\end{array}$ & $\begin{array}{l}\text { Natural and artificial stream } \\
\text { Stream sustaining the city life; abandoned } \\
\text { to natural control } \\
\text { Dredging, controlled stream }\end{array}$ & $\begin{array}{l}\text { People's interest } \\
\text { Scholar's interest }\end{array}$ \\
$1700 \mathrm{~s}$ & $\begin{array}{l}\text { Strong leadership } \\
\text { from king }\end{array}$ \\
$1800 \mathrm{~s}$ & $\begin{array}{l}\text { Unsanitary sewer and slum } \\
1960 \mathrm{~s}\end{array}$ & $\begin{array}{l}\text { Less interest } \\
\text { 1970s-1980s }\end{array}$ \\
$\begin{array}{l}\text { Highway for industrialization } \\
\text { Old market selling everything; declining traffic, } \\
\text { population and environmental contamination }\end{array}$ & \\
\hline & & \\
\hline
\end{tabular}

and pressure from rapid economic development in the 1960s that required more roads and an easing of traffic congestion. That is why, in 1968, the Cheonggye Elevated Highway was constructed over Cheonggyecheon. Table 3.3 summarizes the history of Cheonggyecheon from two aspects: streams status and leaders' attitude to its control.

\subsubsection{Paradigm Change for Urban Development}

There has been a paradigm change and a new vision for this area of Seoul. In 2003, after about 40 years of neglecting Cheonggyecheon, the restoration project was begun following the introduction of environmentally sound and sustainable development (ESSD) with the key idea of urban development sustainability. The paradigm of urban planning is shifting from a growth-oriented or quantitative growth model-by expanding urban spaces based on transport requirements, large-scale investment, development effect, facilities development and strategic point development - to a growth management or qualitative growth model based on humanism and naturalism, pedestrian requirements, quality of life improvement, benefit/management, developing "soft" programs, and a network system.

The project was led by the City of Seoul, especially by the mayor, Lee Myungbak (the President of Republic of Korea later), who showed a clear vision. More than $70 \%$ of the citizens supported the restoration. The vision was to create an environment-friendly city space with an emphasis on nature and people, solving the safety problem related to covered structures, recovering the 600-year-old capital city's historic and cultural significance, promoting balanced regional development, and providing a "hands-on eco experience" to millions of citizen [14].

\subsubsection{Implementation of Cheonggyecheon and Public Participation}

This restoration project had wide-ranging public participation. The master plan included dismantling the elevated highway and the structures covering the stream, 
moving some structures to other places, and building the infrastructure to help restore the stream, including a sewage system, roads, bridges, landscaping, and lighting [15]. During the development process, the general public, specialists, and interest groups formed a citizens' committee and offered their opinions. On the other hand, those opposed criticized the government-led restoration project, and coalesced around main three groups [16]: (1) The first to step forward were academic groups such as the Environmental Sociology Association, the Korea Planners Association and the Environmental Impact Assessment Society. They organized a series of academic debates that disclosed the theoretical and practical drawbacks associated with the civil engineering-focused restoration, such as insufficient ecological considerations, undemocratic procedures, excessive commercial re-development of the surroundings and an unsustainable water flow. (2) There was a strong public and NGO coalition movement, organized by a citizens' coalition, against what was regarded as an undemocratic, anti-environmental and politically manipulated restoration. (3) The last opposing force was made up of more than 60,000 merchants along Cheonggye Road-employing 800,000 workersplus a large number of illegal street vendors. Most shopkeepers were worried about the loss of business during the construction period. The merchants were vehemently opposed to the restoration plan, so they joined the street vendors in sometime violent demonstrations that threatened the project. The merchant group was not only the most recalcitrant but also the most important partner from whom Mayor Lee needed to gain consent in order to carry out the project as planned. Unlike other opposition groups, however, the merchant group's major concern was to safeguard and maximize their private interests, but the group was too fragmented to be effective.

It is most desirable for a stream to receive water from its upper reaches. However, the arguable fact still is that Cheonggyecheon requires additional flow from the Han River to maintain a certain depth throughout the year. This is likely to continue until advanced technology is in place to treat environmental hormones, smell, and the foaming of wastewater, as well as a change in people's perceptions for reusing wastewater.

\subsubsection{Leadership}

Leadership and some measures were necessary to persuade the opposition groups. The City of Seoul took some measures to ease traffic congestion. To gauge the opinions of merchants on the impact of the restoration project on their business, the City of Seoul held public hearings and gave presentations for each commercial block. These steps helped to win over the Cheonggyecheon Residents and Merchants Council and the Cheonggyecheon Merchants Association. Seoul also conducted more than 4,000 interviews with merchants before the start of the demolition work. Based on the opinions collected, measures were devised to address complaints related to inconvenience to businesses. Additional measures were devised for stimulating business activity that considered the unique character of the Cheonggyecheon commercial district, which is made up of several business quarters with widely 
varying interests. In response to academics and NGOs, the Cheonggyecheon Restoration Project helped to restore the long-forgotten history and culture of Seoul. Traditional cultural activities were revived, such as "bridge stepping" on Supyogyo Bridge (when people go out onto the bridge to look at the full moon) and a lantern festival. In addition, the local bridges were restored, and fundamental safety problems were resolved for the Cheonggye Elevated Highway and some of the structures covering the stream.

\subsubsection{After Cheonggyecheon Restoration}

The impact and economic cost/benefit were also assessed. There was the most controversy over the 24-h runoff of 120,000 tons of water from the Han River. This required pumping and large amounts of energy that contribute to environmental problems, such as the greenhouse effect. The most significant change, however, was that millions of visitors went to the restored district. Cultural events have been held almost every day on the Cheonggye Plaza, located at the starting point of the waterway. The plaza has now become the most attractive cultural civic space in central Seoul and visitors are highly satisfied with their experience, as the author stated in the New York Times article.

The Cheonggyecheon restoration is known as the most successful recent example of public policy in Korea. Yet, at the same time, it is still at the center of a controversy because of the evaluation of its character [15]. Cheonggyecheon's restoration has helped to improve downtown Seoul and it is possible to view the project as part of the "ecological modernization" of Seoul [16]. This project was led by the strong political ambition of its initiator. According to the Seoul Development Institute, a prominent partner in this project, willingness to pay 103,309 won per household per year $(8,609 \mathrm{won} / \mathrm{month})$ or 356.2 billion won/year in Seoul was measured after this successful project. This implies that Cheonggyecheon's restoration inspired different thoughts about the quality of life and the willingness to sacrifice for the public good. Citizens are now willing to pay for non-economic value and public benefit. Thus, the social cost: construction + congestion (loss by traffic load) + waterway maintenance over social benefit: savings of repair costs (no highway maintenance) + environmental benefit (willingness to pay) was measured as Benefit over Cost $(B / C)=1.85$ [17].

\subsection{Features of the Compulsory Course}

\subsubsection{Diversity}

One of unique features of the ECLA class is the student's interdisciplinary from either engineering/technology (the Department of Urban Engineering, UE) or sustainability science (the Graduate Program of Sustainability Science, GPSS), as well cultural diversity from all over the world (though the majority of the students are Asian). Students struggle with such diversity during group work, but often mutual benefit is greater and led to desirable outcome. 


\subsubsection{Interactive Dialogues Between Teachers and Students}

Considering the speed of Asia's economic and population growth and the diversity of students, education methods in ECLA was modified from traditional type of information delivery to transmit needed information throughout the process of finding and understanding. Developing effective skills and style for environmental leaders drew the image of environmental leaders through an interview and survey to metaphor the image of leaders, and exercised the creating a vision through consensus building and setting the priorities among vision, in the class. Inclusion, or listening using all available skills and ideas were emphasized in the classroom as well. For example, debate over China's air pollution and climate change; stakeholder analysis of Minamata disease; comparison between Minamata disease and another Japanese experience of Fukushima Daiichi (Nuclear Power plant) aids students to develop the leadership capacity.

Education methods in ECLA showed how we explored the possibilities and requirements for addressing trends in environmental leadership in market-oriented, industrialized, and industrializing economies in Asia during the past several decades, and practiced essential leadership skills prior to APIEL's field exercise.

\subsubsection{Case Studies}

The author communicated with students to discuss the evidence for improvement (or deterioration) in environmental quality by case studies, and the lessons learned from them. Materials used for three case studies were chosen : (1) Minamata disease, a typical example of an industrial pollution problem that Japan has experienced, deal with industrialization in 1960s in Japan and many of Asia country in recent years; (2) China's air pollution case over last three decades, due to an overwhelming reliance on coal for energy production and its effect to climate change associated with current globalization; and (3) Korea's Cheonggyecheon Restoration case to understand recent urbanization in 1990s, and address the importance of public participation. Overall, communication between the authors (teachers) and students "about," "in," and "for" the environment based on case studies enables us to see how students can increase their capacity to play the role of future leaders.

\subsection{Discussion and Conclusion}

This series of ECLA lectures provides environmental issues and leadership lessons learned from history, as well as discourses on industrialization, recent urbanization, and globalization. As such, the Minamata disease issue can be viewed from many perspectives. Stakeholders, including professionals (scientists, policymakers, as well as government and company officials) and citizens each have their roles and 
responsibilities. It is important for environmental leaders in many stakeholder groups to understand these other points of view. In addition, the lessons learned are not only the ones from the past, but also from some of the ongoing problems that are directly linked with modern life.

The authors reviewed the issues to be addressed to educate students to understand and to build leadership skills, as well as the attributes and ethics associated with the complex challenges that we are facing as we prepare for a sustainable future. The lectures include interactive dialogues between teachers and students, and students among themselves, to criticize, understand, persuade, and learn throughout the journey. The authors put emphasize such practices prior to APIEL's field exercise. Because arriving at consensuses vision is always time consuming and a first barrier students have to go through and division of role at field work is of importance.

Therefore, these classes are the "seed" for the field exercises where students can practice what they learn in the class. Reflection of this education method in ECLA on each field excises will be introduced in the part two. The vivid stories of the field exercises will be outlined in Chaps. 4-7 in the second part of this book.

Open Access This article is distributed under the terms of the Creative Commons Attribution Noncommercial License which permits any noncommercial use, distribution, and reproduction in any medium, provided the original author(s) and source are credited.

\section{References}

1. Hillstrom K, Hillstrom LC (2003) Asia: a continental overview of environmental issues. The World's Environments Series. ABC/CLIO, Santa Barbara

2. Gordon JC, Berry JK (2006) Environmental leadership equals essential leadership. Yale University, New Haven \& London

3. Sonnenfeld DA, Mol APJ (2006) Environmental reform in Asia: comparisons, challenges, next steps. J Environ Dev Volume 15(2):112-137

4. Minamata City (2007) Minamata disease. Its history and lessons. Minamata City Planning Division, Kumamoto

5. Ishimure M (1990) Paradise in the sea of sorrow: our Minamata disease. Livial Monnet, trans. Yamaguchi Publishing House, Kyoto (First published in Japanese as Kugai Jodo: Waga Minamata-byo by Kodansha, Tokyo 1972)

6. Harada M (2004) Minamata disease Tshushima S and George ST. trans. Kumamoto Nichinichi Shimbun Culture and Information Center, Kumamoto (First published in Japanese as Minamata-byo by Iwanami Shoten Publishers, Tokyo 1972)

7. Ui J (1992) Minamata disease. In: Ui J (ed) Industrial pollution in Japan. United Nations University Press, Tokyo

8. Sugiyama S (2005) Minamatabyou jirei ni okeru gyousei to kagakusya to media no sougo sayou. In: Fujigaki Y (ed) Case analysis and theoretical concepts for science and technology studies. University of Tokyo Press, Tokyo (in Japanese)

9. Nishimura H, Okamoto T (2001) Science of Minamata disease (Minamatabyo no kagaku). Nihon Hyoron Sha, Tokyo (in Japanese)

10. Pollution in Japan-Our Tragic Experiences, Study Group for Global Environment and Economics, Ministry of Environment (2006) Annual report on the environment in Japan 2006 
11. Economy EC (2006) China's Environmental Challenge Asia Studies Council on Foreign Relations, Testimony Before the U.S.-China Economic and Security Review Commission Hearing on Major Challenges Facing the Chinese Leadership

12. Zeng N, Ding Y, Pan J, Wang H, Gregg J (2008) Climate change-the Chinese challenge. SCIENCE 319:730-731

13. New York Times (2009) Peeling back pavement to expose Watery Havens, 17 July 2009

14. Shin JH, Lee IK (2006) Cheonggyecheon restoration in Seoul, Korea. Proc Inst Civil EngCivil Eng 159(4):162-170

15. Cho MR (2010) The politics of urban nature restoration - the case of Cheonggyecheon restoration in Seoul. Korea IDPR 32(2):2010. doi:10.3828/idpr.2010.05

16. Cho MR (2006) Developmental politics and green progress. Environment and Life, Seoul (in Korean)

17. Seoul Development Institute (2005) A study on the basic plan of Cheonggyecheon place marketing strategy. Seoul Development Institute, Seoul 